\title{
The Interaction of Genetic and Environmental Factors in the Etiology of Hypertension
}

\author{
J. KUNES $\check{S}^{1,2}$, J. ZICHA ${ }^{1,2}$ \\ ${ }^{1}$ Center for Cardiovascular Research and ${ }^{2}$ Institute of Physiology, Academy of Sciences of the \\ Czech Republic, Prague, Czech Republic
}

Received June 5, 2009

Accepted October 30, 2009

\begin{abstract}
Summary
Essential hypertension is a major risk factor for several cardiovascular diseases. It is a complex trait resulting from the interactions of multiple genetic and environmental factors. Moreover, not only genetic but also epigenetic inheritance plays a significant role. One can speculate that hypertension develops as a consequence of "errors" in well-coordinated regulatory systems of blood pressure. Errors in the cascade of molecular, biochemical and genetic processes, which regulate blood pressure, have finally enough potential to result in hypertension. Numerous environmental factors surrounding the organism during its development should influence the expression of genetic information. However, despite the considerable research effort, it is still difficult to identify all genes and/or other genetic determinants leading to essential hypertension and other cardiovascular diseases. This is mainly because these diseases usually become a medical problem in adulthood, although their roots might be traced back to earlier stages of ontogeny. The link between distinct developmental periods (e.g. birth and adulthood) should involve changes in gene expression involving epigenetic phenomena. The purpose of the present paper is to bring a piece of light on gene-environmental interactions potentially implicated in the pathogenesis of hypertension.
\end{abstract}

\section{Key words}

Metabolic syndrome • Hypertension • Genes • Environment • Epigenetics

\section{Corresponding author}

J. Kuneš, Institute of Physiology, Academy of Sciences of the Czech Republic, Vídeňská 1083, 14220 Prague 4, Czech Republic. Fax: +420 24106 2488. E-mail: kunes@biomed.cas.cz

\section{Introduction}

Essential hypertension is a major risk factor for cardiovascular diseases such as heart attack, congestive heart failure, stroke and peripheral vascular disease. It is a complex trait resulting from the interactions of multiple genetic and environmental determinants. The inheritance of hypertension has been debated for many years since Pickering and Platt clashed over the form of the blood pressure (BP) distribution. Pickering (1959) suggested that BP, like other traits as height or weight, was continuously distributed, whereas Platt (1947) believed that it was bimodal. Recently, heritability estimates of blood pressure, or the genetic contribution to blood pressure variation, range from 30 to $50 \%$ (Timberlake et al. 2001). There is growing evidence that complex interactions among multiple genes and multiple environmental factors play an important role in determining an individual's risk of various common diseases including hypertension (Kuneš and Zicha 2006). Gibson (1996) stressed that gene-gene interactions and gene-environmental interactions must be ubiquitous given the complexities of intermolecular interactions that are necessary to regulate gene expression and the hierarchical complexity of quantitative traits.

One can speculate that hypertension develops as a consequence of "errors" in well-coordinated regulatory systems of blood pressure. Errors in the cascade of molecular, biochemical and genetic processes, which regulate blood pressure, have finally enough potential to result in hypertension. Because these errors could not be huge, their determination is sometimes difficult. 
Furthermore, a simple comparison of two strains, one normotensive and one hypertensive, could not answer the question what is a primary and what is the secondary. The use of special models and genetic approaches with gene manipulations are big advantages of the experimental approach, which should help to understand the etiology of human hypertension and their effective prevention. The aim of this review is to outline some aspects of geneenvironmental interaction in the etiology of hypertension with special attention to the critical developmental periods in which the organism is exceptional sensitive to environmental stimuli.

\section{Difficulties with the analysis of multifactorial diseases}

Interest in the genetic basis of human diseases has spanned the centuries and discoveries of diseaserelated genes often suggest that tests to predict people at risk of future disease will soon be available. Progress in the battle against human disease is being accelerated by the availability of genomic information for human, mice and other organisms. The techniques of molecular biology and genetics as well as particular knowledge emerging from these genome projects have revolutionized the process of localizing and identifying genes involved in the disease. More than 1,000 human disease genes have already been identified and partially characterized, $97 \%$ of which are known to cause monogenic diseases (Jimenez-Sanchez et al. 2001). Major process that is generally referred as "positional cloning" lead to identification of the genes underlying diseases such as cystic fibrosis (Kerem et al. 1989,
Riordan et al. 1989), chronic granulomatous disease (Royer-Pokora et al. 1986), X-linked muscular dystrophies (Savitsky et al. 1995) and many others (for review see Botstein and Rich 2003). However, one should keep in mind that our knowledge could not always be translated into useful clinical applications. This is mainly true for common complex diseases. As our understanding of the role of genetics and the use of genebased markers extend to complex multifactorial disease, physicians will have to learn how to recognize patients with higher than general risk. This will be complicated if multiple low-frequency alleles and/or low-penetrance alleles are involved. Initial analyses of the completed chromosomal sequences suggest that the number of human genes is lower than expected (about 30,000) (Peltonen and McKusick 2001). However, according to the splicing theory one gene could be the origin of several proteins and these give the bases of many active peptides and metabolites (Fig. 1). Because not only changes on the gene level but even more the changes on the level of proteins and peptides play a role in the most of pathological processes, the cause of multifactorial diseases is difficult to be recognized. Therefore the search for genetic determinants of the multifactorial diseases should not only be the hunting for genes but also for proteins and metabolites. It also seems likely that obvious deleterious mutations in the coding sequences of genes are responsible for only a fraction of the differences in disease susceptibility between individuals, and that sequence variants affecting gene splicing and regulation must play an important part in determining disease susceptibility.

\section{Why?}

Fig. 1. The complexity of a transformation of genetic information.
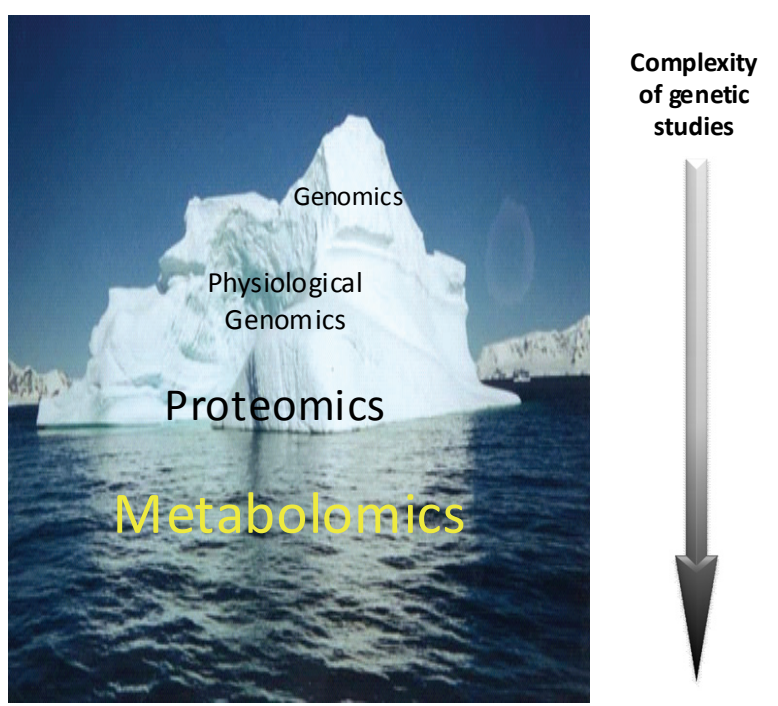

Human genome

$\sim 30000$ genes

at least 4 splicing

variants

120000 proteins

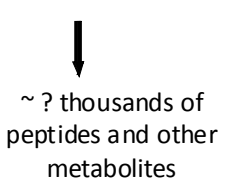

peptides and other metabolites 


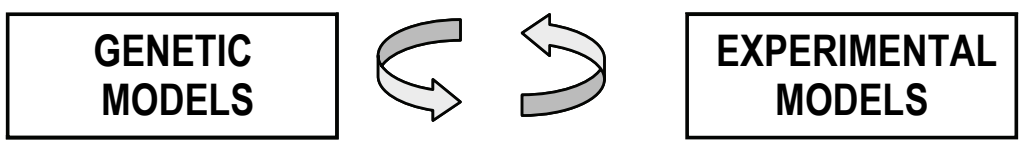

Fig. 2. Genetic approaches to the study of genetic determinants of experimental hypertension.
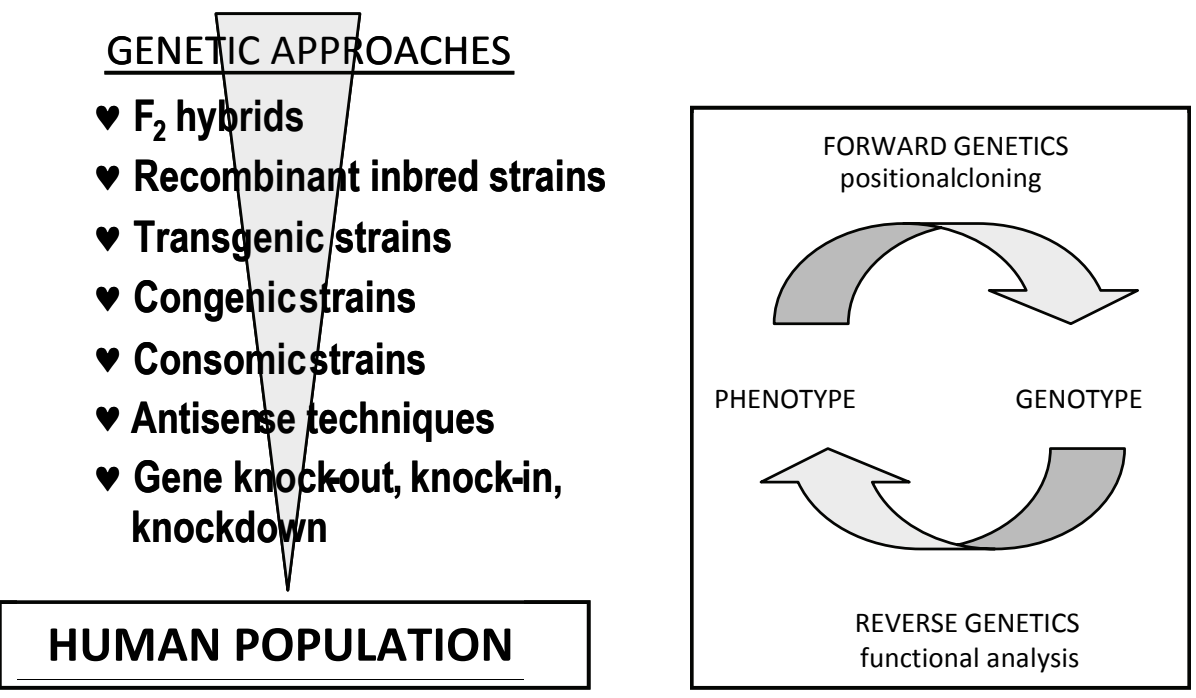

Human genetics has been very successful at identifying susceptibility genes for rare Mendelian diseases. However, this strategy has largely been unsuccessful when applied to identify susceptibility genes for common complex multifactorial diseases such as hypertension, diabetes, obesity, atherosclerosis, etc.

Genetic analysis can distinguish between genes that are causal for a trait and those that may be involved in secondary responses. This analysis can identify chromosomal regions associated with particular quantitative trait loci (QTLs). Advances in molecular markers, especially microsatelite repeats, and recently developed computer analysis programs have accelerated the identification of chromosomal regions associated with hypertension in the rat (for review see Rapp 2000). However, the small contributions of individual genes and the heterogeneity of patients, make genetic studies of essential hypertension difficult. Up to now, several different genes have been found to play a role in Mendelian hypertension in humans (Doris 2002). Studies on animal models show that there is a diversity of genes influencing BP, suggesting that a larger number of genes are likely to be involved in hypertension development. Therefore, it is more plausible that many genes of small effect, which display effects modification in the presence of some environmental factors, are responsible for the etiology of human hypertension.

Many different rat and mouse models of genetic hypertension have been developed with different etiology of hypertension (Rapp 2000, Cicila 2000, Glazier et al. 2002, Svenson et al. 2003). These different genetic models provide an opportunity to investigate the genetic determinants of different types of hypertension, but one must be careful to transfer the results obtained in animal models to human essential hypertension.

It should be kept in mind that it is not sufficient to identify a trait difference in two different inbred strains. Does not matter that this difference has a physiological relevance to blood pressure regulation, it is difficult to ascertain that this trait difference is a primary genetic cause for BP increase. We have several reasons for such a statement. The observed BP phenotype of particular inbred strain is the sum of the contributions of many genes, i.e. both "plus" alleles (leading to higher BP) and "minus" alleles (leading to lower BP) (Rapp 1983). Moreover, the changes in genes were fixed during the inbreeding of any particular inbred strain. Therefore, the association of particular markers or traits with BP could result from chance rather than being the cause of genetic difference, in part, for blood pressure differences observed between two inbred strains. The genetic approaches like segregating populations, congenic or consomic strains, recombinant inbred strains, transgenic or knock-out animals must be used to evaluate the meaning of differences between two inbred strains (Fig. 2).

Because there is more information about genome than about the gene function, the reverse genetics should 


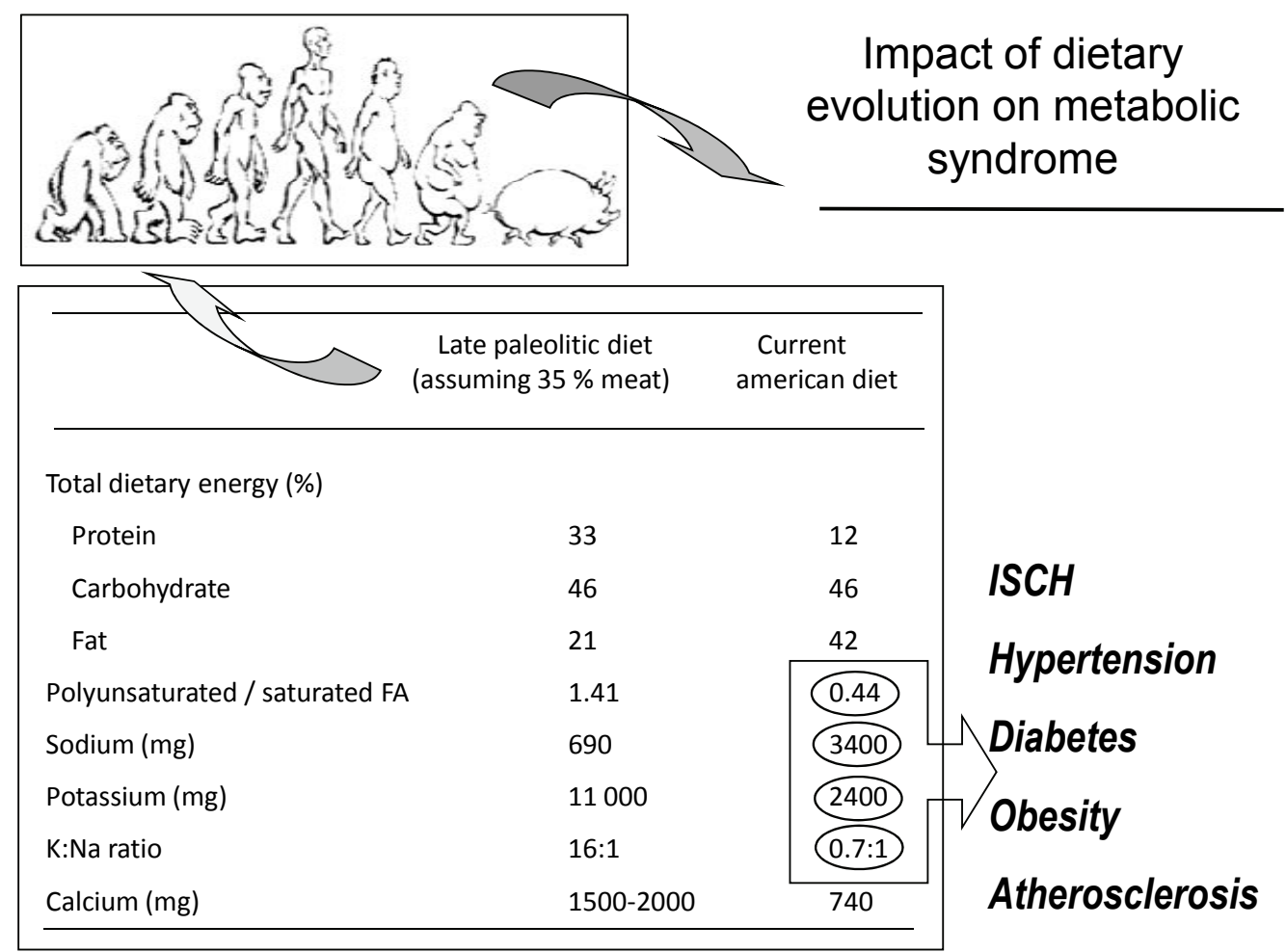

Fig. 3. The impact of dietary evolution on metabolic syndrome development.

solve this problem (Fig. 2). Therefore the cooperation between molecular biologists and physiologists is highly expected. Indeed, the recent big progress in molecular biology and genomic techniques and its integration with physiological techniques started the era of functional and/or physiological genomics (Jacob 1999, Veerasingham et al. 2004). This is a multidisciplinary approach to facilitate gene identification and to study their function. It also includes the detection of sequence variations and characterization of aberrations in gene functions leading to the disease. As only a small proportion of the sequence variations in our genomes will probably have functional impacts, identifying this subset of sequence variants will be one of the major challenges of the next decade. Moreover, the follow-up work of understanding how these and other genetic variations regulate the phenotypes of human cells, tissues, and organs may well occupy biomedical researchers for all of the $21^{\text {st }}$ century. A more recent addition to the functional genomics is proteomics. Proteins, gene products, are final tools for the realization of genetic information. Recently, proteome analysis has been introduced to analyze differential protein expression and cellular protein composition even in cardiovascular medicine. The new techniques for protein analysis were also developed. While two-dimensional polyacrylamide gel electrophoresis (2D-PAGE) was very successful for the analysis of the abundant and moderately expressed proteins, at present one struggles to identify proteins expressed at low levels. The sensitivity of mass spectrometry has increased considerably during recent years to detect low amount of synthesized proteins. Proteomics now allows to examine global alterations in protein expression in the diseased tissues, and will provide new insights into the cellular mechanisms involved in cardiovascular dysfunction.

\section{Gene-environment interaction}

Human genome was originally selected under different daily living conditions and has remained unchanged since the agriculture revolution 10,000 years ago. Accumulating evidence suggested that the discrepancies between our Paleolithic genome and "modern" diet and lifestyle could play a significant role in the ongoing epidemics of obesity, hypertension, diabetes, atherosclerosis and other symptoms of metabolic syndrome (Fig. 3) (Eaton et al. 1988, Eaton and Eaton 2003). This was achieved by the changes from wild and unprocessed food to diet high in fat, sugar and salt, suggesting that $\mathrm{K}: \mathrm{Na}$ ratio progressively changed as changed polyunsaturated:saturated fatty acid ratio. It 


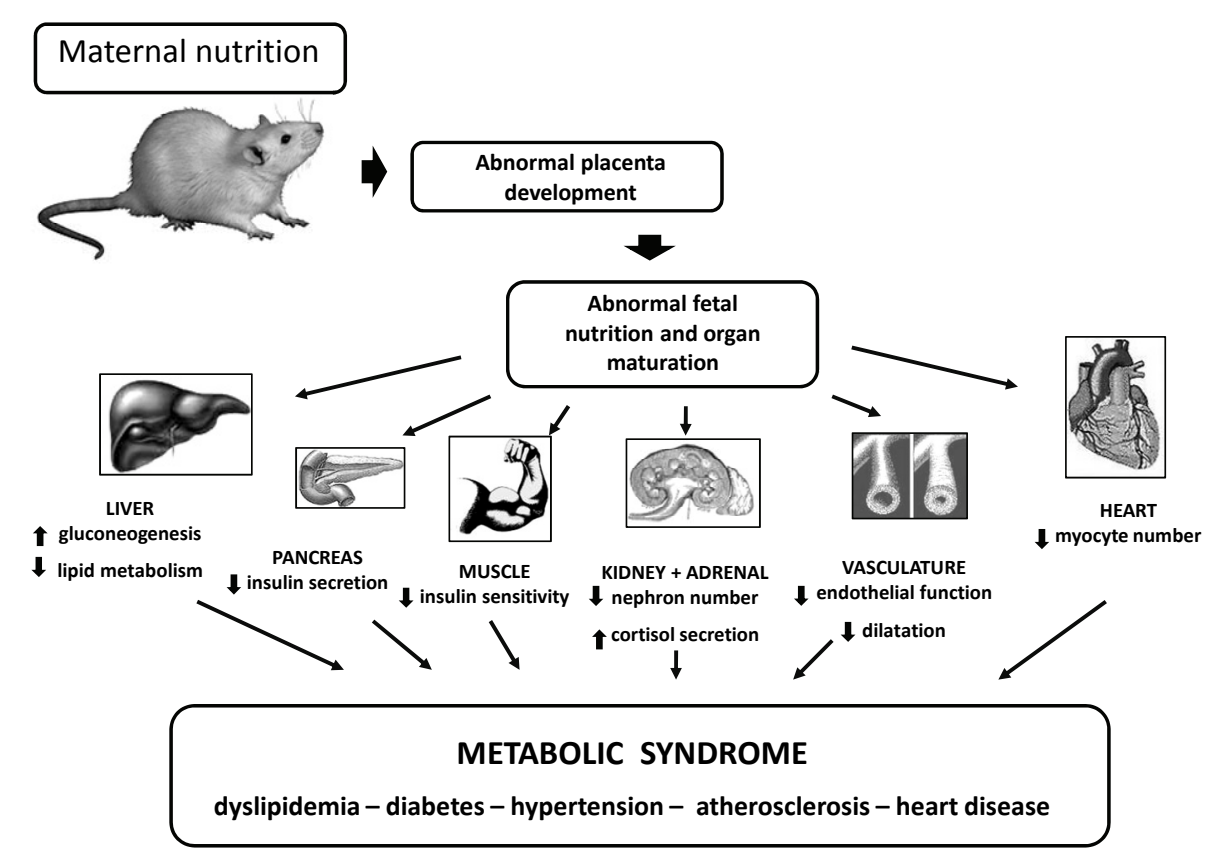

Fig. 4. The relation between maternal nutrition and abnormal fetal organ maturation and their links to metabolic syndrome development in the adulthood.

should be intensively studied if this is the major trigger of these epidemiological problems. It was also suggested that sedentary lifestyle and overweight are major clinical and economical problems in modern societies. The worldwide epidemic of excess weight is due to imbalance between physical activity and dietary energy intake. Sedentary lifestyle, unhealthy diet, and consequent overweight and obesity markedly increase the risk of subsequent cardiac events such as non-fatal arrhythmia, myocardial infarction, sudden cardiac death, etc. (Myers et al. 2002). Regular physical activity (45-60 min per day) prevents unhealthy weight gain and obesity, whereas sedentary behaviors such as watching television promote them. The best long-term results may be achieved when physical activity produces an energy expenditure of at least 200-500 kcal/day. Regular moderate physical activity (mainly aerobic exercise), a healthy diet, and avoiding unhealthy weight gain are effective and safe ways to prevent and treat cardiovascular diseases. Moreover, there is plenty of proofs that exercise lowers blood pressure and beneficially influence serum lipids (Eaton and Eaton 2003). If beneficial effect from exercise is more effective in some developmental periods, this should be tested in large epidemiological studies.

It is true that some environmental factors, e.g. stress, dietary factors (salt, fat), temperature etc. could be the causal mechanisms leading to a given disease (Greenland and Rothman 1998, Kuneš and Zicha 2006) especially if they influence the organism in „critical developmental periods“ and/or „developmental windows“ (Zicha and Kuneš 1999, Kuneš and Zicha 2006).

Recently the association between low birth weight and raised blood pressure in later life has been studied (Barker et al. 1989, Huxley et al. 2000, de Boo and Harding 2006, Eriksson et al. 2007). According to this "programming hypothesis", an impairment of intrauterine environment deprives the fetus from its optimal development leading to the cardiovascular complications in later life. Although most clinical and experimental studies support this fetal programming hypothesis in relation to adult hypertension, there is still controversy regarding the cause and mechanisms underlying this phenomenon. A general schema expects the changes in maternal nutrition leading to abnormal fetal nutrition, which directly or indirectly influenced growth and maturation of various organs (Fig. 4).

However, not all studies support this theory, suggesting that rather body size in early adolescence than birth weight is more important (Falkner et al. 2004). Eriksson et al. (2007) have shown in set of 2003 people selected from the Helsinki birth cohort that two different paths of fetal, infant and childhood growth precede the development of hypertension in adult life. In one that was associated with more severe hypertension in people who tended to be obese, small body size at birth and during infancy were followed by rapid growth. In the other, 
which was associated with less severe hypertension, slow linear growth in utero and during infancy were followed by persisting small body size. This is in a good agreement with the idea that particular environmental stimuli might affect the expression of genetic information in distinct developmental windows (Kuneš and Zicha 2006). By using of recombinant inbred (RI) strains we have even demonstrated that some phenotypic abnormalities (e.g. relative kidney weight) related to the development of hypertension may really precede the blood pressure changes (Hamet et al. 1998). More recently, animal studies and indirect human studies support the hypothesis that congenital deficit in nephron number could be one of a possible common pathophysiologic denominators between low birth weight and subsequent adult hypertension (Zandi-Nejad et al. 2006).

The link between two distinct developmental periods (birth and adulthood) should involve changes in gene expression involving epigenetic phenomena. Thus, environmental changes in the intrauterine period or shortly after birth may ultimately lead to altered gene expression via epigenetic mechanisms resulting in an increased susceptibility to chronic disease in adulthood (Waterland and Jirtle 2004). This epigenetic process of imprinting is thought to particularly affect many of the genes regulating fetal and placental growth (Reik et al. 2001).

\section{Epigenetic control of gene expression}

It is well known that gene expression patterns in the process of differentiation are controlled through the DNA sequence. However, the second mechanism which is not directly related to the sequence of DNA, and termed "epigenetic", is intensively studied (Egger et al. 2004, Nafee et al. 2007, Burdge et al. 2007). Four main types of epigenetic inheritance - DNA methylation, chromatin remodeling, genomic imprinting and longrange control of chromatin structure have been described (see Nafee et al. 2007). It was even demonstrated that although the epigenetic pattern is not a part of DNA sequence itself, is heritably transmitted during cell division (Reik et al. 2001, Surani 2001).

The particular types of epigenetic inheritance are a complex process that depends on the participation of numerous components of epigenetic machinery. Transitions between different chromatin states are dynamic and seem to depend on a balance between factors that sustain a transcriptionally silent state and those that promote a transcriptionally active state (Jaenisch and Bird 2003). Some mammalian genes are expressed preferentially from the paternal or maternal allele and are said to be genomically imprinted. Most imprinted genes are found in clusters, and the bestcharacterized imprinted domain comprises the paternally expressed insulin-like growth factor 2 (IGF2) gene. This gene shares regulatory element with the maternally expressed $\mathrm{H} 19$ gene, which is located only $100 \mathrm{~kb}$ downstream. Recently we have demonstrated strong segregation of $I G F 2$ genotype with plasma triglycerides in population of $\mathrm{F}_{2}$ hybrids derived from Prague hypertriglyceridemic and Lewis progenitors (Kadlecová et al. 2008). There was also segregation between this genotype and blood pressure changes after blockade of either renin-angiotensin system or NO synthase. One could speculate that any epigenetic modification of $I G F 2$ gene might be involved in these regulatory processes.

Typical example of epigenetic inheritance is the inheritance of the coat color gene agouti in the mouse (Wolff et al. 1998, Morgan et al. 1999). Several agouti viable yellow alleles $\left(A^{\text {hyy }}\right.$ or $A^{I A P}$ ) regulate the alternative production of black and yellow pigment in individual hair follicles. The coat color of mice with such an allele varies from yellow over mottled to wild-type agouti. Transcription of this gene occurs in the skin during short period when the yellow subapical band is formed at the beginning of each hair growth cycle. When methylated, the agouti gene is expressed only in the hair follicles as in wild-type mice. On the other hand, unmethylated gene causes the yellow coat color. It was demonstrated that dietary methyl supplementation of $a / a$ dams with extra folic acid, vitamin $B_{12}$, choline and betaine alters the phenotype of their $A^{h v y} / a$ offspring (Waterland et al. 2003). Thus $A^{\text {hvy }}$ expression, already known to be modulated by imprinting, maternal epigenetic inheritance and strain-specific modifications, might also be modulated by maternal diet. These results also suggested that through maternal epigenetic inheritance the diet might positively affect health and longevity of the offspring (Wolff et al. 1998) because yellow mice become also obese and develop tumor with age.

\section{Perspectives}

There is no doubt that not only genetic but also environmental factors are very important for the regulation and maintenance of blood pressure. There is growing evidence that complex interactions among 
multiple genes and multiple environmental factors play an important role in determining an individual's risk of various common diseases including hypertension. Because of complex trait it is still not simple to recognize individual genes, which should be a simple target for genetic manipulation. Although some experimental results suggested certain possibilities, it is difficult to apply these techniques in humans. For example, gene therapy of 5-day-old SHR resulting in the long-term expression of $\mathrm{AT}_{1}$ receptor antisense transcript successfully prevented the development of this type of genetic hypertension (Iyer et al. 1996, Martens et al. 1998), but the effect of such treatment in adult animals was only transient (Katovich et al. 1999).

Probably more perspective and effective should be the recommendation for the modification of lifestyle. Salt restriction to less than $6 \mathrm{~g} /$ day, maintenance of appropriate body weight, higher physical exercise, restriction of stress, augmented fruit and vegetable consumption, etc. should be a standard recommendation of each physicians to their patients. Not only patients but the whole population must be motivated for lifestyle changes because most of "civilization" diseases including hypertension have their roots in the earlier stages of ontogeny. Finally one can say that if "sensitive" genome enters "toxic" environment during particular critical developmental period, there is very high probability that disease will develop.

\section{Conflict of Interest}

There is no conflict of interest.

\section{Acknowledgements}

This work has been partially supported by AV0Z 50110509, by the research projects GA CR 305/08/0139 and 305/09/0336 as well as by the project of Ministry of Education of the Czech Republic 1M0510.

\section{References}

BARKER DJP, OSMOND C, GOLDING J, KUH D, WADSWORTH MEJ: Growth in utero, blood pressure in childhood and adult life, and mortality from cardiovascular disease. Br Med J 298: 564-567, 1989.

BOTSTEIN D, RICH N: Discovering genotypes underlying human phenotypes: past successes for mendelian disease, future approaches for complex disease. Nat Genet 33: 228-237, 2003.

BURDGE GC, HANSON MA, SLATER-JEFFERIES JL, LILLYCROP KA: Epigenetic regulation of transcription: a mechanism for inducing variations in phenotype (fetal programming) by differences in nutrition during early life? Br J Nutr 97: 1036-1046, 2007.

CICILA GT: Strategy for uncovering complex determinants of hypertension using animal models. Curr Hypertens Rep 2: $1-10,2000$.

DE BOO HA, HARDING JE: The developmental origins of adult disease (Barker) hypothesis. Aust N Z J Obstet Gynaecol 46: 4-14, 2006.

DORIS P: Hypertension genetics, single nucleotide polymorphisms, and the common disease: common variant hypothesis. Hypertension 39: 323-331, 2002.

EATON SB: Stone agers in the fast lane: chronic degenerative diseases in evolutionary perspective. Am J Med 84: 739$749,1988$.

EATON SB, EATON SB: An evolutionary perspective on human physical activity: implications for healts. Comp Biochem Physiol A 136: 153-159, 2003.

EGGER G, LIANG G, APARICIO A, JONES PA: Epigenetics in human disease and prospects for epigenetic therapy. Nature 429: 457-463, 2004.

ERIKSSON JG, FORSÓN TJ, KAJANTIE E, OSMOND C, BARKER DJP: Childhood growth and hypertension in later life. Hypertension 49: 1414-1421, 2007.

FALKNER B, HULMAN S, KUSHNER H: Effect of birth weight on blood pressure and body size in early adolescence. Hypertension 43: 203-207, 2004.

GIBSON G: Epistasis and pleiotropy as natural properties of transcriptional regulation. Theor Popul Biol 49: 58-89, 1996.

GLAZIER AM, NADEU JH, AITMAN TJ: Finding genes that underlie complex traits. Sciences 298: 2345-2349, 2002. 
GREENLAND S, ROTHMAN KJ: Concepts of interaction. In: Modern Epidemiology ROTHMAN KJ, GREENLAND S. (eds), Lippincott-Raven, Philadelphia, PA, 1998, pp 329-342.

HAMET P, PAUSOVA Z, DUMAS P, SUN YL, TREMBLAY J, PRAVENEC M, KUNES J, KRENOVA D, KREN $\mathrm{V}$ : Newborn and adult recombinant inbred strains: a tool to search for genetic determinants of target organ damage in hypertension. Kidney Int 53: 1488-1492, 1998.

HUXLEY RR, SHIEL AW, LAW CM: The role of size at birth and postnatal catch-up growth in determining systolic blood pressure: a systemic review of the literature. J Hypertens 18: 815-831, 2000.

IYER SN, LU D, KATOVICH MJ, RAIZADA MK: Chronic control of high blood pressure in the spontaneously hypertensive rat by delivery of angiotensin type 1 receptor antisense. Proc Natl Acad Sci U S A 93: 9960-9965, 1996.

JACOB JH: Physiological genetics: aplication to hypertension research. Clin Exp Pharmacol Physiol 26: 530-535, 1999.

JAENISCH R, BIRD A: Epigenetic regulation of gene expression: how the genome integrates intrinsic and environmental signals. Nat Genet 33: 245-254, 2003.

JIMENEZ-SANCHEZ G, CHILDS B, VALLE D: Human disease genes. Nature 409: 853-835, 2001.

KADLECOVÁ M, DOBEŠOVÁ Z, ZICHA J, KUNEŠ J: Abnormal Igf2 gene in Prague hereditary hypertriglyceridemic rats: its relation to blood pressure and plasma lipids. Mol Cell Biochem 314: 37-43, 2008.

KATOVICH MJ, GELBAND CH, REAVES P, WANG HW, RAIZADA MK: Reversal of hypertension by angiotensin II type 1 receptor antisense gene therapy in the adult SHR. Am J Physiol 277: H1260-H1264, 1999.

KEREM B, ROMMENS JM, BUCHANAN JA, MARKIEWICZ D, COX TK, CHAKRAVARTI A, BUCHWALD M, TSUI LC: Identification of the cystic fibrosis gene: genetic analysis. Science 245: 1073-1080, 1989.

KUNEŠ J, ZICHA J: Developmental windows and environment as important factors in the expression of genetic information: a cardiovascular physiologist's view. Clin Sci 111: 295-305, 2006.

MARTENS JR, REAVES PY, LU D, KATOVICH MJ, BERECEK KH, BISHOP SP, RAIZADA MK, GELBAND $\mathrm{CH}$ : Prevention of renovascular and cardiac pathophysiological changes in hypertension by angiotensin II type 1 receptor antisense gene therapy. Proc Natl Acad Sci U S A 95: 2664-2669, 1998.

MORGAN HD, SUTHERLAND HG, MARTIN DI, WHITELAW E: Epigenetic inheritance at the agouti locus in the mouse. Nat Genet 23: 314-318, 1999.

MYERS J, PRAKASH M, FROELICHER V, DO D, PARTINGTON S, ATWOOD JE: Exercise capacity and mortality among men referred for exercise testing. $N$ Engl J Med 346: 793-801, 2002.

NAFEE TM, FARRELL WE, CARROLL WD, FRYER AA, ISMAIL KMK: Epigenetic control of fetal gene expression. BJOG 115: 158-168, 2008.

PELTONEN L, MCKUSICK VA: Dissecting human disease in the postgenomic era. Science 291: 1224-1229, 2001.

PICKERING GW: The nature of essential hypertension. Lancet ii: 1027-1028, 1959.

PLATT R: Heredity in hypertension. Q J Med 16: 111-133, 1947.

RAPP JP: A paradigm for identification of primary genetic causes of hypertension in rats. Hypertension 5: I198-I203, 1983.

RAPP JP: Genetic analysis of inherited hypertension in the rat. Physiol Rev 8: 135-172, 2000.

REIK W, DEAN W, WALTER J: Epigenetic reprogramming in mammalian development. Science 293: 1089-1093, 2001.

RIORDAN JR, ROMMENS JM, KEREM B, ALON N, ROZMAHEL R, GRZELCZAK Z, ZIELENSKI J, LOK S, PLAVSIC N, CHOU JL: Identification of the cystic fibrosis gene: cloning and characterization of complementary DNA. Science 245: 1066-1073, 1989.

ROYER-POKORA B, KUNKEL LM, MONACO AP, GOFF SC, NEWBURGER PE, BAEHNER RL, COLE FS, CURNUTTE JT, ORKIN SH: Cloning the gene for an inherited human disorder - chronic granulomatous disease-on the basis of its chromosomal location. Nature 322: 32-38, 1986. 
SAVITSKY K, BAR-SHIRA A, GILAD S, ROTMAN G, ZIV Y, VANAGAITE L, TAGLE DA, SMITH S, UZIEL T, SFEZ S, ASHKENAZI M, PECKER I, FRYDMAN M, HARNIK R, PATANJALI SR, SIMMONS A, CLINES GA, SARTIEL A, GATTI RA, CHESSA L, SANAL O, LAVIN MF, JASPERS NG, TAYLOR AM, ARLETT CF, MIKI T, WEISSMAN SM, LOVETT M, COLLINS FS, SHILOH Y. A single ataxia telangiectasia gene with a product similar to PI-3 kinase. Science 268: 1749-1753, 1995.

SURANI MA: Reprogramming of genome function through epigenetic inheritance. Nature 414: 122-128, 2001.

SVENSON KL, BOGUE MA, PETERS LL: Identifying new mouse models of cardiovascular disease: a review of highthroughput screens of mutagenized and inbred strains. J Appl Physiol 94: 1650-1659, 2003.

TIMBERLAKE DS, O'CONNOR DT, PARMER RJ: Molecular genetics of essential hypertension: recent results and emerging strategies. Curr Opin Nephrol Hypertens 10: 71-79, 2001.

VEERASINGHAM SJ, SELLERS KW, RAIZADA MK: Functional genomics as an emerging strategy for the investigation of centralmechanisms in experimental hypertension. Prog Biophys Mol Biol 84: 107-123, 2004.

WATERLAND RA, JIRTLE RL: Transposable elements: targets for early nutritional effects on epigenetic gene regulation. Mol Cell Biol 23: 5293-5300, 2003.

WATERLAND RA, JIRTLE RL: Early nutrition, epigenetic changes at transposons and imprinted genes, and enhanced susceptibility to adult chronic diseases. Nutrition 20: 63-68, 2004.

WOLFF GL, KODELL RL, MOORE SR, COONEY CA: Maternal epigenetics and methyl supplements affect agouti gene expression in $A^{v y} / a$ mice. FASEB J 12: 949-957, 1998.

ZANDI-NEJAD K, LUYCKX VA, BRENNER BM: Adult hypertensuion and kidney disease. The role of fetal programming. Hypertension 47: 502-508, 2006.

ZICHA J, KUNEŠ J: Ontogenetic aspects of hypertension development: analysis in the rat. Physiol Rev 79: 1227-1282, 1999. 